\title{
Antimicrobial Activity of Root Canal Irrigants associated with Cetrimide against Biofilm and Planktonic Enterococcus faecalis
}

\author{
${ }^{1}$ Camila Almeida Nascimento, ${ }^{2}$ Mario Tanomaru-Filho, ${ }^{3}$ Norberto Batista Faria-Junior \\ ${ }^{4}$ Gisele Faria, ${ }^{5}$ Juliane Maria Guerreiro-Tanomaru
}

\begin{abstract}
Aim: To evaluate the antibacterial activity of sodium hypochlorite $(\mathrm{NaOCl})$ and chlorhexidine $(\mathrm{CHX})$ alone or associated with cetrimide (CTR), and QMiX against biofilm and planktonic Enterococcus faecalis (E. faecalis) [American type culture collection (ATCC) 29212]
\end{abstract}

Materials and methods: The solutions $2.5 \% \mathrm{NaOCl}, 2.5 \%$ $\mathrm{NaOCl}+0.2 \% \mathrm{CTR}, 2 \% \mathrm{CHX}, 2 \% \mathrm{CHX}+0.2 \% \mathrm{CTR}, 0.2 \% \mathrm{CTR}$, and QMiX were evaluated. E. faecalis biofilms were induced for 14 days on bovine dentin blocks. The irrigants were evaluated after contact with $E$. faecalis suspension and biofilm for 1 and 3 minutes. After that, serial decimal dilutions were made and plated on tryptic soy agar (TSA) medium. Plates were incubated for 24 hours at $37^{\circ} \mathrm{C}$ and the colony-forming unit (CFU) $1 \mathrm{ml}$ was determined. Data were subjected to ANOVA and Tukey's tests at $5 \%$ significance.

Results: All microorganisms were eliminated by direct contact of the irrigants with planktonic cells. Only $\mathrm{NaOCl}$ and $\mathrm{NaOCl}$ + CTR were able to completely eliminate the microorganisms by direct contact with $E$. faecalis biofilm. $\mathrm{CHX}$ presented effectiveness similar to CHX + CTR CTR, and QMiX after 1 minute of contact and similar to $\mathrm{NaOCl}$ and $\mathrm{NaOCl}+\mathrm{CTR}$ after 3 minutes ( $p>0.05$ ), but was unable to completely eliminate the microorganisms. CTR and QMiX did not differ from each other.

Conclusion: CTR addition to $\mathrm{CHX}$ and $\mathrm{NaOCl}$ solutions did not improve the antimicrobial activity against biofilm. All evaluated irrigants and associations presented activity against planktonic E. faecalis. Only $\mathrm{NaOCl}$ and $\mathrm{NaOCl}+\mathrm{CTR}$ eliminated biofilm after 1 and 3 minutes of direct contact.

Clinical relevance: Addition of CTR does not modify the antibiofilm effectiveness of $\mathrm{CHX}$ and $\mathrm{NaOCl}$.

Keywords: Biofilm, Chlorhexidine, Enterococcus faecalis, Sodium hypochlorite, Root canal irrigant.

\footnotetext{
${ }^{1} \mathrm{MSc}$ Student, ${ }^{2,4,5}$ Professor, ${ }^{3} \mathrm{PhD}$ Student

${ }^{1-5}$ Department of Restorative Dentistry, Araraquara Dental School, São Paulo State University (UNESP), Araraquara São Paulo, Brazil

Corresponding Author: Mario Tanomaru-Filho, Professor Department of Restorative Dentistry, Araraquara Dental School, São Paulo State University (UNESP), Araraquara São Paulo, Brazil, Phone: 551633016390, e-mail: tanomaru@ uol.com.br
}

How to cite this article: Nascimento CA, Tanomaru-Filho M, Faria-Junior NB, Faria G, Guerreiro-Tanomaru JM. Antimicrobial Activity of Root Canal Irrigants associated with Cetrimide against Biofilm and Planktonic Enterococcus Faecalis. J Contemp Dent Pract 2014;15(5):603-607.

Source of support: Nil

Conflict of interest: None

\section{INTRODUCTION}

Disinfection of the root canal system is essential for endodontic treatment success. ${ }^{1,2}$ Irrigating solutions are used during root canal preparation in order to reduce the endodontic microbiota. ${ }^{3,4}$ E. faecalis, a commonly detected microorganism in endodontic treatment failures ${ }^{1,5}$ is able to survive under unfavorable conditions and organize in biofilm.

Sodium hypochlorite $(\mathrm{NaOCl})$ in concentrations from 0.5 to $6 \%$ is the most widely used irrigant in endodontics due to its antimicrobial activity and ability to dissolve pulp tissue. ${ }^{6,7}$ Chlorhexidine (CHX) is also recommended as a root canal irrigant, despite its lower antibacterial action against microorganisms in biofilm. ${ }^{6}$

Cetrimide (CTR) is a cationic surfactant used to decrease the cohesion between the extracellular matrix polymers and the bacterial cell wall. ${ }^{8,9}$ Moreover, it can eliminate $E$. faecalis in biofilm after 1 minute of direct contact at a concentration of $0.2 \%,{ }^{10}$ and after only 30 seconds of contact at $0.5 \%{ }^{11}$ CTR at $0.2 \%$, associated with ethylenedia minetetracetic acid (EDTA) or citric acid at 15\% eliminates biofilm after brief direct contact. ${ }^{12}$ When associated with other solutions, CTR lowers the surface tension, conferring the irrigant greater ability to penetrate into the dentin tubules and anatomical irregularities of the root canal system. ${ }^{9,13}$

QMiX is an irrigating solution composed of $\mathrm{CHX}$ at $2 \%$, EDTA and CTR. ${ }^{14}$ This irrigant has demonstrated antibacterial activity comparable to $\mathrm{NaOCl}$ at $6 \%$ in dentin infected by E. faecalis. ${ }^{9,13}$ QMiX showed stronger antibacterial activity against biofilm and planktonic E. faecalis in comparison with conventional $\mathrm{CHX} .{ }^{15}$ However, QMiX was unable to eliminate and remove microorganisms in biofilm from oral microbiota. $^{14}$

The aim of the present study was to evaluate the antibacterial action of $\mathrm{NaOCl}$ at $2.5 \%$ and $\mathrm{CHX}$ at $2 \%$ associated 
with CTR at $0.2 \%$, and QMiX against biofilm and planktonic E. faecalis. The null hypothesis is that these solutions present similar effectiveness against the two forms of microbial organization.

\section{MATERIALS AND METHODS}

\section{Direct Contact of the Bacterial Suspension with the Irrigating Solutions}

The bacterial suspension was adjusted to $1.0 \times 10^{7}$ colonyforming units per milliliter (CFU ml$^{-1}$ ) using a spectrophotometer (600 Plus, Femto, São Paulo, SP, Brazil). Samples $(1.45 \mathrm{ml})$ of each irrigant were placed in Eppendorf test tubes and $50 \mu \mathrm{l}$ aliquots of $E$. faecalis suspension were added to each tube. ${ }^{16}$ The direct contact periods of the irrigating solutions with the bacterial suspension ranged from 1 to 3 minutes. The decimal serial dilutions were performed using in the first three tubes a solution-specific neutralizing agent (Table 1). The fourth, fifth and sixth tubes contained sterile saline.

At the end of the process, three aliquots of $20 \mu \mathrm{l}$ from each dilution were seeded on tryptic soy agar (TSA) plates and incubated at $37^{\circ} \mathrm{C}$ under microaerophilic conditions. After 48 hours of incubation, the counting CFU were performed in order to determine the mean of the three areas of bacterial growth. The mean CFU counts were log 10 transformed and subjected to ANOVA and Tukey's tests at a significance level of $5 \%$.

\section{Direct Contact of the Biofilm with the Irrigating Solutions}

Root segments from bovine central incisors were sectioned (Isomet-Buehler, Lake Bluff, IL, USA) to obtain blocks measuring $5 \times 5 \times 0.7 \mathrm{~mm}$ (width $\times$ length $\times$ thickness) and were sterilized by autoclaving. ${ }^{17,18}$

Enterococcus faecalis (ATCC- 29212) biofilms were allowed to grow on the dentin blocks in a shaking incubator for 14 days at $37^{\circ} \mathrm{C}$, under microaerophilic conditions. ${ }^{18}$ The culture medium $(\mathrm{BHI})$ of each specimen was replaced every
48 hours. The purity of the E. faecalis strain was tested by Gram stain and colony morphology.

For the direct contact test, the dentin blocks containing biofilm were immersed in $1 \mathrm{ml}$ of each irrigating solution and combinations (Table 1) for 1 or 3 minutes. After the experimental period, each dentin block was rinsed under saline and transferred to test tubes containing glass beads (3 $\mathrm{mm}$ in diameter) and $1 \mathrm{ml}$ of neutralizing agent. ${ }^{15,16,19}$ Each tube was shaken for 60 seconds (Vortex AP 56, Phoenix, Araraquara, SP, Brazil) in order to resuspend the microorganisms attached to the dentin blocks. Then, serial decimal dilutions were prepared and plated on TSA medium.

\section{RESULTS}

Figures 1 and 2 show the mean $\log _{10} \mathrm{CFU} \mathrm{m}{ }^{-1}$ of $E$. faecalis after direct contact of the irrigants and associations with the bacterial suspension and biofilm for 1 and 3 minutes.

According to the results, all the irrigating solutions and associations were able to eliminate the planktonic microorganisms after 1 and 3 minutes of direct contact (Graph 1). $\mathrm{NaOCl}$ and $\mathrm{NaOCl}+\mathrm{CTR}$ were able to eliminate the microorganisms in biofilm. CHX, CHX + CTR, CTR, and QMiX presented similar results after 1 minute of direct contact with

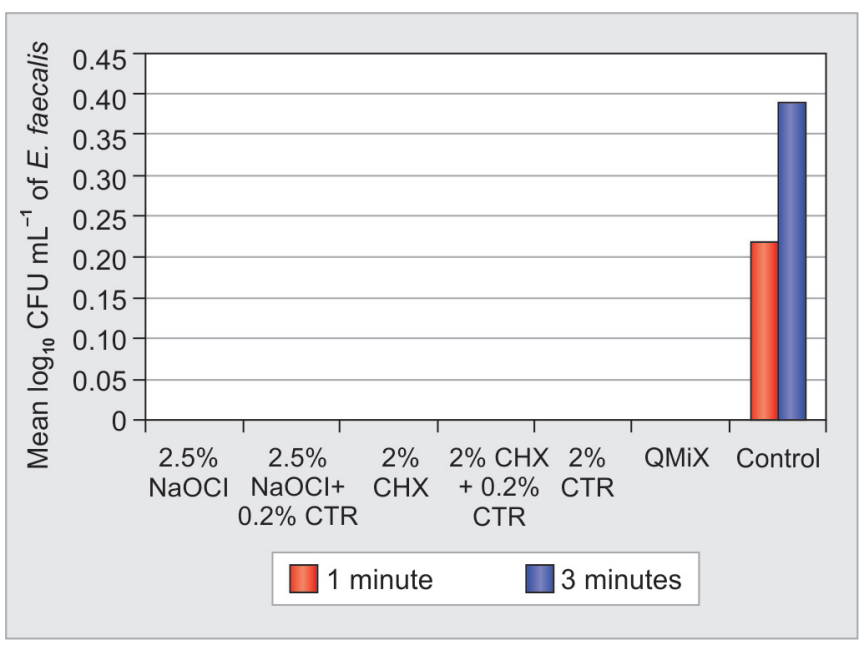

Fig. 1: Mean CFU $\mathrm{ml}^{-1}$ of $E$. faecalis after direct contact of the bacterial suspension with the irrigating solutions for 1 or 3 minutes

Table 1: Irrigating solutions and combinations, with their respective neutralizing agents (used after direct contact with bacterial suspension or biofilm)

\begin{tabular}{lll}
\hline Groups & Irrigating solutions & Neutralizing solutions \\
\hline I & $2.5 \% \mathrm{NaOCl}^{*}$ & $1 \%$ sodium thiosulfate \\
II & $2.5 \% \mathrm{NaOCl}^{* *} 0.2 \% \mathrm{CTR}^{* *}$ & $1 \%$ sodium thiosulfate $+3 \%$ tween $80^{* *}+0.7 \% \alpha-$ lecithin $_{0.7 \% * *}$ \\
III & $2 \% \mathrm{CHX}^{*}$ & $3 \%$ Tween $80+0.7 \% \alpha$-lecithin \\
IV & $2 \% \mathrm{CHX}+0.2 \% \mathrm{CTR}$ & $3 \%$ Tween $80+0.7 \% \alpha$-lecithin \\
V & $0.2 \% \mathrm{CTR}$ & $3 \%$ Tween $80+\alpha$-lecithin at $0.7 \%$ \\
VI & $\mathrm{QMiX}^{* * *}$ & $3 \%$ Tween $80+0.7 \% \alpha$-lecithin \\
VII & $0.85 \%$ Saline solution & $0.85 \%$ Saline solution \\
\hline
\end{tabular}

${ }^{*}$ Compounding Pharmacy at the School of Pharmacy of Araraquara, Araraquara, SP, BR; **Sigma-Aldrich Brasil Ltda. São Paulo, SP, BR; ***Dentsply Tulsa Dental Specialties, Tulsa, OK, USA 
biofilm ( $\mathrm{p}>0.05)$. CHX alone and CHX combined with CTR showed antibacterial activity similar to $\mathrm{NaOCl}$ and $\mathrm{NaOCl}+$ CTR $(\mathrm{p}>0.05)$ after direct contact for 3 minutes, but were unable to eliminate $E$. faecalis. CTR and QMiX did not present significant difference from each other $(p>0.05)$. After 3 minutes of contact, QMiX had lower antibiofilm action than $\mathrm{NaOCl}$ and $\mathrm{CHX}$, alone or associated with CTR (Graph 2).

\section{DISCUSSION}

Enterococcus faecalis has been used for evaluation of antimicrobial agents due to its association with endodontic treatment failures, ${ }^{1,20}$ and ability to organize in biofilm. Hydroxyapatite, ${ }^{16,18}$ human dentin, ${ }^{21,22}$ bovine dentin ${ }^{6,14}$ and polystyrene membrane ${ }^{21}$ have been used as substrates for biofilm formation. E. faecalis biofilm shows organization after growing on bovine dentin blocks for 14 days. ${ }^{18}$ Bovine dentin has been widely used ${ }^{14,17,18}$ due to its similarities with human dentin. Biofilm maturity may influence its response to antimicrobial agents..$^{21,23,24}$

The direct contact test quantifies viable microorganisms after different periods of contact with irrigating solutions. ${ }^{10,25}$ The use of neutralizing agents prevents the occurrence of false negative results. ${ }^{16,19,26}$ Tween 80 and lecithin are chlorhexidine-neutralizing. ${ }^{4}$ Sodium thiosulfate inactivates sodium hypochlorite. , $^{3,15,27}$

In the present study, all the irrigating solutions and associations evaluated promoted elimination of planktonic microorganisms. Abdullah et $\mathrm{al}^{26}$ observed that E. faecalis is eliminated after 1 minute of contact with $\mathrm{NaOCl}$ at $3 \%$, and Gomes et $\mathrm{al}^{28}$ verified elimination of planktonic microorganisms after less than 30 seconds of contact with CHX at $2 \%$. However, Bidar et $\mathrm{al}^{29}$ observed that $2.5 \%$ did

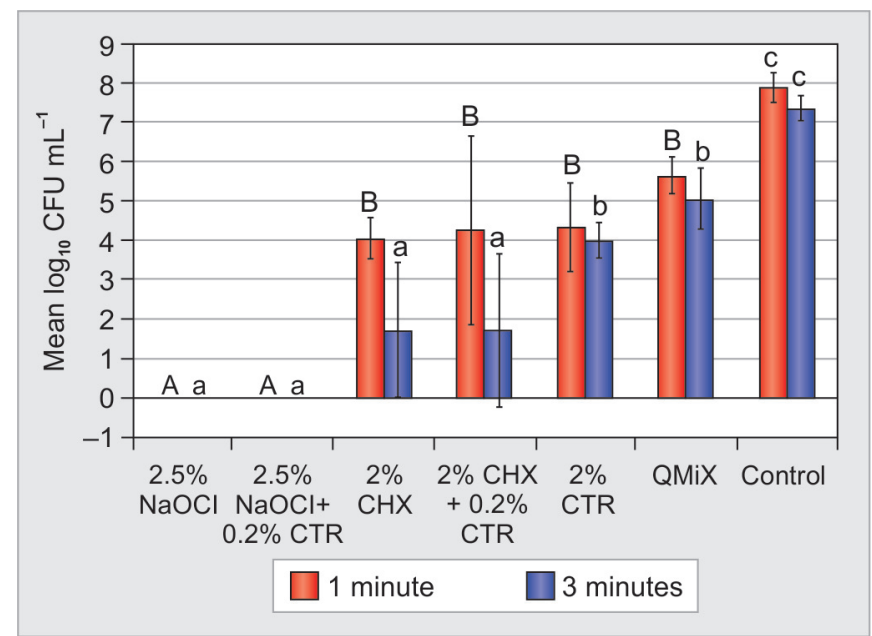

Fig. 2: Means and standard deviations for the CFU $\mathrm{ml}^{-1}$ of E. faecalis after direct contact of biofilm with the irrigants for 1 or 3 minutes. Upper case letters refer to the results for contact periods of 1 minute, and lower case letters indicate contact for 3 minutes. Different letters indicate statistically significant difference between the groups within the same experimental period $(p<0.05)$ not completely eliminate planktonic cells of E. faecalis in 15 minutes. When CHX was combined with CTR in concentrations lower than those used in the present study, the resulting solution demonstrated ability to eliminate two E. faecalis strains in planktonic phase after only 10 seconds. ${ }^{30}$ QMiX showed similar results were observed after 5 seconds of contact. ${ }^{15}$

The results of the present study demonstrate that the irrigating solutions present lower activity against microorganisms in biofilm, confirming the greater resistance of bacteria in this form of bacteria in this form of organization. ${ }^{15,26,30} \mathrm{NaOCl}$ demonstrated effectiveness in eliminating E. faecalis biofilm after short contact periods, while CHX was unable to eliminate microorganisms after 1 minute. The limited ability of CHX to eliminate bacterial biofilm has been demonstrated by colony counting methodology, ${ }^{26,31}$ scanning electron microscopy, and confocal laser scanning microscopy. ${ }^{6,14,17,32}$ In the present study, despite its similarities with $\mathrm{NaOCl}, \mathrm{CHX}$ was unable to eliminate the microorganisms after 3 minutes of biofilm contact. This observation is in agreement with Ariaz-Moliz et al, ${ }^{11}$ who evaluated CHX in concentrations of up to $4 \%$ with contact periods of 2 minutes.

CTR has demonstrated antibiofilm activity. Baca et al ${ }^{10}$ demonstrated the ability of CTR at $2 \%$ to eliminate E. faecalis biofilm after 1 minute of direct contact. These authors report antibiofilm action comparable to that of $\mathrm{NaOCl}$ at $1 \%$ and greater than $\mathrm{CHX}$ at $2 \%$. CTR at $0.0078 \%$ eliminates microorganisms after 2 minutes of direct contact with E. faecalis biofilm, whereas CTR associated with CHX was capable of eliminate biofilm after 30 seconds of contact. ${ }^{11}$ Addition of CTR enhances the antibiofilm activity of solutions such as EDTA, citric acid, ${ }^{12}$ lactic acid,,${ }^{25}$ and Biopure (MTAD). ${ }^{16}$ The present study did not show increase in antibiofilm activity by the addition of CTR to CHX.

Stojicic et $\mathrm{a}^{15}$ observed greater antibiofilm activity for QMiX compared with CHX after 1 and 3 minutes of contact with E. faecalis biofilm isolated from root canals (VP3-181 and Gel 31). In the present study, the contact of QMiX with biofilm for 1 minute did not show increased antimicrobial action, corroborating with Ordinola-Zapata et al, ${ }^{14}$ who observed the poor cleaning ability when QMiX were applied for 5 minutes on multispecies biofilm.

Some dentin components may inactivate the action of endodontic antimicrobial agents. ${ }^{30,33-35}$ Therefore, CHX, CTR and QMiX may have displayed lower antibacterial action due to the presence of bovine dentin used to substrate. Biofilm elimination has been observed in other studies, where polystyrene ${ }^{11}$ and hydroxyapatite ${ }^{15}$ were used as substrates.

Biofilm restricts penetration of antimicrobial agents into the bacterial cells due to the presence of a polymeric matrix 
involving the microorganisms. ${ }^{36}$ Accordingly, mature biofilms confer greater resistance against antimicrobial agents to bacterial cells, which are organized into overlapping layers deeply embedded in the matrix..$^{24,37}$ Thus, the use of mature biofilm (14 days old $)^{18}$ and dentin as the substrate may explain the difficulties for its complete biofilm elimination observed in the present study.

\section{CONCLUSION}

All evaluated irrigants and associations presented activity against planktonic E. faecalis. Only $\mathrm{NaOCl}$ and $\mathrm{NaOCl}$ + CTR eliminated biofilm after 1 and 3 minutes of direct contact. Addition of CTR does not modify the antibiofilm effectiveness of $\mathrm{CHX}$ and $\mathrm{NaOCl}$.

\section{ACKNOWLEDGMENTS}

The authors of this work would like to thank the CAPESCoordenação de Aperfeiçoamento de Pessoal de Nível Superior-for financial support.

\section{REFERENCES}

1. Siqueira JF Jr, Rôças IN. Clinical implications and microbiology of bacterial persistence after treatment procedures. J Endod 2008 Nov;34(11):1291-1301.

2. Sjögren U, Figdor D, Persson S, Sundqvist G. Influence of infection at the time of root filling on the outcome of endodontic treatment of teeth with apical periodontitis. Int Endod J 1997 Sep;30(5):297-306.

3. Aranda-Garcia AR, Guerreiro-Tanomaru JM, Faria-Júnior NB, Chavez-Andrade GM, Leonardo RT, Tanomaru-Filho M, Bonetti-Filho I. Antibacterial effectiveness of several irrigating solutions and the Endox Plus system: an ex vivo study. Int Endod J 2012 Dec;45(12):1091-1096.

4. Dornelles-Morgental R, Guerreiro-Tanomaru JM, de FariaJúnior NB, Hungaro-Duarte MA, Kuga MC, Tanomaru-Filho M. Antibacterial efficacy of endodontic irrigating solutions and their combinations in root canals contaminated with Enterococcus faecalis. Oral Surg Oral Med Oral Pathol Oral Radiol Endod $2011 \mathrm{Sep} ; 112(3): 396-400$.

5. Stuart CH, Schwartz SA, Beeson TJ, Owatz CB. Enterococcus faecalis: its role in root canal treatment failure and current concepts in retreatment. J Endod 2006 Feb;32(2):93-98.

6. Ordinola-Zapata R, Bramante CM, Cavenago B, Graeff MS, Gomes de Moraes I, Marciano M, Duarte MA. Antimicrobial effect of endodontic solutions used as final irrigants on a dentin biofilm model. Int Endod J 2012 Feb;45(2):162-168.

7. Stojicic S, Zivkovic S, Qian W, Zhang H, Haapasalo M. Tissue dissolution by sodium hypochlorite: effect of concentration, temperature, agitation and surfactant. J Endod 2010 Sep;36(9):1558-1562.

8. Simões M, Pereira MO, Vieira MJ. Effect of mechanical stress on biofilms challenged by different chemicals. Water Res 2005 Dec;39(20):5142-5152.

9. Wang Z, Shen Y, Ma J, Haapasalo M. The effect of detergents on the antibacterial activity of disinfecting solutions in dentin. J Endod 2012 Jul;38(7):948-953.
10. Baca P, Junco P, Arias-Moliz MT, González-Rodríguez MP, Ferrer-Luque CM. Residual and antimicrobial activity of final irrigation protocols on Enterococcus faecalis biofilm in dentin. J Endod 2011 Mar;37(3):363-366.

11. Arias-Moliz MT, Ferrer-Luque CM, González-Rodríguez MP, Valderrama MJ, Baca P. Eradication of Enterococcus faecalis biofilms by cetrimide and chlorhexidine. J Endod 2010 Jan;36(1):87-90.

12. Ferrer-Luque CM, Arias-Moliz MT, González-Rodríguez MP, Baca P. Antimicrobial activity of maleic acid and combinations of cetrimide with chelating agents against Enterococcus faecalis biofilm. J Endod 2010 Oct;36(10):1673-1675.

13. Ma J, Wang Z, Shen Y, Haapasalo M. A new noninvasive model to study the effectiveness of dentin disinfection by using confocal laser scanning microscopy. J Endod 2011 Oct;37(10):1380-1385.

14. Ordinola-Zapata R, Bramante CM, Garcia RB, de Andrade FB, Bernardineli N, de Moraes IG, Duarte MA. The antimicrobial effect of new and conventional endodontic irrigants on intraorally infected dentin. Acta Odontol Sc and 2013 MayJul;71(3-4):424-431.

15. Stojicic S, Shen Y, Qian W, Johnson B, Haapasalo M. Antibacterial and smear layer removal ability of a novel irrigant, QMiX. Int Endod J 2012 Apr;45(4):363-371.

16. Pappen FG, Shen Y, Qian W, Leonardo MR, Giardino L, Haapasalo M. In vitro antibacterial action of Tetraclean, MTAD and five experimental irrigation solutions. Int Endod J 2010 Jun;43(6):528-535.

17. Del Carpio-Perochena AE, Bramante CM, Duarte MA, Cavenago BC, Villas-Boas MH, Graeff MS, Bernardineli N, de Andrade FB, Ordinola-Zapata R. Biofilm dissolution and cleaning ability of different irrigant solutions on intraorally infected dentin. J Endod 2011 Aug;37(8):1134-1138.

18. Guerreiro-Tanomaru JM, de Faria-Júnior NB, Duarte MA, Ordinola-Zapata R, Graeff MS, Tanomaru-Filho M. Comparative analysis of Enterococcus faecalis biofilm formation on different substrates. J Endod 2013 Mar;39(3):346-350.

19. Guerreiro-Tanomaru JM, Morgental RD, Flumignan DL, Gasparini F, Oliveira JE, Tanomaru-Filho M. Evaluation of $\mathrm{pH}$, available chlorine content, and antibacterial activity of endodontic irrigants and their combinations against Enterococcus faecalis. Oral Surg Oral Med Oral Pathol Oral Radiol Endod $2011 \mathrm{Jul} ; 112(1): 132-135$.

20. Mattigatti S, Ratnakar P, Moturi S, Varma S, Rairam S. Antimicrobial effect of conventional root canal medicaments vs propolis against Enterococcus faecalis, Staphylococcus aureus and Candida albicans. J Contemp Dent Pract 2012;13:305-309.

21. Liu H, Wei X, Ling J, Wang W, Huang X. Biofilm formation capability of Enterococcus faecalis cells in starvation phase and its susceptibility to sodium hypochlorite. J Endod 2010 Apr;36(4):630-635.

22. Norrington DW, Ruby J, Beck P, Eleazer PD. Observations of biofilm growth on human dentin and potential destruction after exposure to antibiotics. Oral Surg Oral Med Oral Pathol Oral Radiol Endod 2008 Apr;105(4):526-529.

23. Shen Y, Stojicic S, Haapasalo M. Antimicrobial efficacy of chlorhexidine against bacteria in biofilms at different stages of development. J Endod 2011 May;37(5):657-661.

24. Wang Z, Shen Y, Haapasalo M. Effectiveness of endodontic disinfecting solutions against young and old Enterococcus faecalis biofilms in dentin canals. J Endod 2012 Oct;38(10):1376-1379.

25. Arias-Moliz MT, Baca P, Ordóñez-Becerra S, GonzálezRodríguez MP, Ferrer-Luque CM. Eradication of enterococci 
biofilms by lactic acid alone and combined with chlorhexidine and cetrimide. Med Oral Patol Oral Cir Bucal 2012 Sep 1;17(5):e902-e906.

26. Abdullah M, Ng YL, Gulabivala K, Moles DR, Spratt DA. Susceptibilties of two Enterococcus faecalis phenotypes to root canal medications. J Endod 2005 Jan;31(1):30-36.

27. Giardino L, Ambu E, Savoldi E, Rimondini R, Cassanelli C, Debbia EA. Comparative evaluation of antimicrobial efficacy of sodium hypochlorite, MTAD, and Tetraclean against Enterococcus faecalis biofilm. J Endod $2007 \mathrm{Jul} ; 33(7): 852-855$.

28. Gomes BP, Ferraz CC, Vianna ME, Berber VB, Teixeira FB, Souza-Filho FJ. In vitro antimicrobial activity of several concentrations of sodium hypochlorite and chlorhexidine gluconate in the elimination of Enterococcus faecalis. Int Endod J 2001 Sep;34(6):424-428.

29. Bidar M, Hooshiar S, Naderinasab M, Moazzami M, Orafaee H, Naghavi N, et al. Comparative study of the antimicrobial effect of three irrigant solutions (chlorhexidine, sodium hypochlorite and chlorhexidinated MUMS). J Contemp Dent Pract 2012 Jul 1;13(4):436-439.

30. Portenier I, Waltimo T, Ørstavik D, Haapasalo M. Killing of Enterococcus faecalis by MTAD and chlorhexidine digluconate with or without cetrimide in the presence or absence of dentin powder or BSA. J Endod 2006 Feb;32(2):138-141.
31. Dunavant TR, Regan JD, Glickman GN, Solomon ES, Honeyman AL. Comparative evaluation of endodontic irrigants against Enterococcus faecalis biofilms. J Endod 2006;32:527-531.

32. Clegg MS, Vertucci FJ, Walker C, Belanger M, Britto LR. The effect of exposure to irrigant solutions on apical dentin biofilms in vitro. J Endod 2006 May;32(5):434-437.

33. Haapasalo HK, Sirén EK, Waltimo TM, Ørstavik D, Haapasalo MP. Inactivation of local root canal medicaments by dentin: an in vitro study. Int Endod J 2000 Mar;33(2):126-131.

34. Morgental RD, Singh A, Sappal H, Kopper PM, Vier-Pelisser FV, Peters OA. Dentin inhibits the antibacterial effect of new and conventional endodontic Irrigants. J Endod 2013 Mar;39(3): 406-410.

35. Portenier I, Haapasalo H, Orstavik D, Yamauchi M, Haapasalo $\mathrm{M}$. Inactivation of the antibacterial activity of iodine potassium iodide and chlorhexidine digluconate against Enterococcus faecalis by dentin, dentin matrix, type-I collagen, and heat-killed microbial whole cells. J Endod 2002 Sep;28(9):634-637.

36. Donlan RM, Costerton JW. Biofilms: survival mechanisms of clinically relevant microorganisms. Clin Microbiol Rev 2002 Apr;15(2):167-193.

37. Roberts ME, Stewart PS. Modelling protection from antimicrobial agents in biofilms through the formation of persister cells. Microbiology 2005 Jan;151(Pt 1):75-80. 